International Journal of

Advanced Science and Convergence

\title{
Rule-based Machine Vision System on Clear Empty Glass Base Inspection of Foreign Materials for Philippine MSMEs
}

\author{
James Roy B. Santos' ${ }^{1}$, Raymund M. Lozada ${ }^{2}$ and Mark Joseph B. Enojas ${ }^{3}$ \\ ${ }^{1}$ Bachelor of Engineering, Technological University of the Philippines- Taguig, Taguig City, 1630, Philippines \\ ${ }^{2}$ Electrical and Allied Department, Technological University of the Philippines-Taguig, Taguig City, 1630, \\ Philippines \\ ${ }^{3}$ Bachelor of Engineering and Allied Department, Technological University of the Philippines-Taguig, Taguig \\ City, 1630, Philippines
}

\begin{abstract}
Background/Objectives: The Philippine government through the Department of Science and Technology (DOST) helps the micro, small, and medium enterprises (MSMEs) to support and sustain growth and address their needs on availing cost-effective solutions. Methods/Statistical analysis: Most of the MSMEs which apply clear bottles for their products use manual inspection. These are prone to human error that leads to poor product qualities and rejects. Findings: To address these problems, this study presents a cost-effective solution by a rule-based machine vision system for clear empty glass base inspection. A method on proper setup for the inspection is presented and validated through an in-line loop on a wedge conveyor machine prototype. A minimal setup time was achieved by experimenting different lighting techniques. Improvements/Applications: The use of back light illumination is suggested for good image processing quality with minimal cost. The implementation of a rule-based inspection in this setup results to a high speed of 9000-18000 bottles per hour (bph) with consistent repeatability and superior accuracy.
\end{abstract}

\section{Index Terms}

Automated optical inspection, back light illumination, industrial automation, machine vision system, rule-based

\footnotetext{
Corresponding author: James Roy B. Santos

jamesroysantos04@gmail.com

- Manuscript received July 29, 2019.

- Revised August 30, 2019; Accepted September 20, 2019.

- Date of publication September 30, 2019.

(1) The Academic Society of Convergence Science Inc.

2619-8150 @ 2019 IJASC. Personal use is permitted, but republication/redistribution requires IJASC permission.
} 


\section{INTRODUCTION}

A noble way that the government of the Philippines is doing is to improve productivity of the MSMEs in the Philippines. The DOST-NCR implementing the Small Enterprise Technology Upgrading Program (SET-UP) encourages and assists small and medium enterprise to adapt innovative technologies to leverage sound operations with high productivity [1]. Cost-effective solutions would benefit the MSMEs in the adaption of the innovative techniques. For MSMEs under the food and beverages which makes use of bottles in their products such as vinegars, bagoong, jams, and other Filipino food and beverages can benefit in the solutions being provided in this program. One of the challenges for productions like this is the transition from manual to automated operations. The Bottles, prior to its filling process, requires careful inspection. In this note, human error can be a threat to production, hence results to poor productivity in terms of quality and speed of production.

A survey from several manufacturing companies was conducted to determine the top five defects encountered before filling the bottles. Three companies were visited, not to mention the names for confidentiality. The survey tells that most of the defects are from the presence of foreign materials. Some other defects on the list are lip crack, side wall crack, thread crack, and residual liquid defects, as shown in Fig. 1.

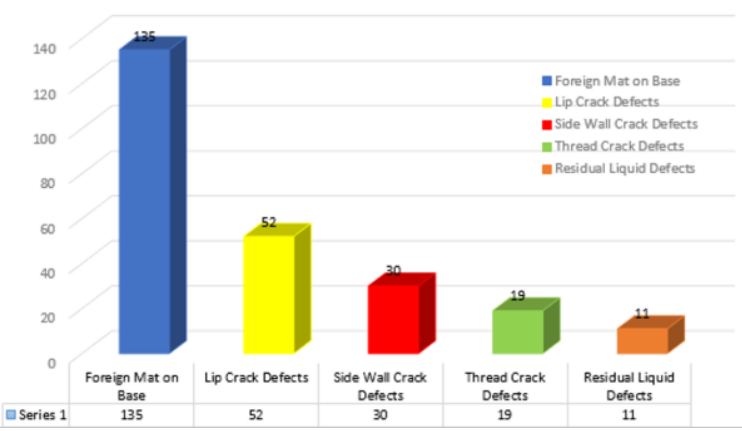

Fig. 1. Top 5 chronic and common defects encountered prior to filling process.

The academic institutions also contribute in addressing such needs by providing solutions evaluated based on realistic situations through prototyping. This study provides a cost-effective means of inspection of clear-empty glass bottle base from foreign materials through a rule-based machine vision system. The rule-based system is described to have certain rules for accepting and rejecting evaluated bottles through a vision system. The study also presents an optimal setup for inspection with high accuracy and speed with optimal camera working distance from the object and focal length of the lens.
The succeeding section discussions are as follows: Section II presents the Literature Review, Section III describes the methodology, Section IV discusses the results of the experiments, and Section V contains the conclusion.

\section{LITERATURE REVIEW}

\section{A. Development of computer aided solutions in empty glass bottle inspection}

An extensive application of image processing gave rise to a lot of automation opportunities in the manufacturing industries. As early as 1980-1990s, using of computers and cameras for food quality assurance have been studied and applied [2]. Bottling companies take advantage of these innovative solutions. Early developments make use of different strategies in bottle inspection. The basic setup makes use of a digital camera to take photos. These photos will be transmitted to be processed and evaluated in a computer with an algorithm for assessing and giving judgements whether pass or fail. An illumination is needed to complete the task for this evaluation. The digital camera should also be calibrated in order to produce the exact image. Therefore, the focal length of the lens of the camera does a lot of influence to the captured image. Different parts of the bottle can be inspected; the mouth, the body, or the base [3] in order to extract the feature of the bottle.

The automated visual inspection for bottling basically aims to 1) give quality inspections, rejecting those that are defective or did not meet the criteria, 2) assure good quality by giving feedback prior to the production filling stage, and 3) gather information or parameters that affects the production [4]. The bottle inspection process using automated visual inspection can be simplified in three stages: image acquisition, locating objects, and measurements and assessments. Such tasks can be accomplished today with the use of high definition and intelligent cameras and several techniques or algorithms to ensure good quality products.

\section{B. Complexity of Classifying Systems}

The classifying systems acquire very delicate role in processing images. It should be able to generalize parameters. Selection of parameters is a difficult task for such systems. One way of addressing challenges is through a fuzzy support vector machine [5-6]. A large data set which in turn will be a fuzzy set is used to run the system to be able to generalize. This means that an automated system is also needed for data gathering which in turn will be another large task. After the data has been gathered, several functions, algorithms, and optimization techniques are run to successfully classify things. 
Neural systems on the other hand are good classifiers for this purpose. However, it relies on a large number of samples or data sets. As described by some researchers, it is having poor extrapolation and opaque reasoning [7].

\section{Rule-based systems - faster classifying system}

The rule-based systems are much suitable for realtime applications because of its good performance. Early in the 1970s, the rule-based system has been studied [8-10] and even used for various applications such as in research laboratories, automated vehicles, traffic analysis, and industry[11-13], but can still be considered to be in its infancy because of a lot of developments that can still be studied and made, treating some issues in the system type. Several soft wares are developed which uses logic operators for rules definition [14]. These rules are used in intelligent cameras or in the integrated software for compatibility and easy programming. Instead of gathering huge amount of data to train, test, and validate the intelligent networks, the rule-based systems only impose several rules for classification. In result, a faster response time in decision making can be done, just as applied to a system with intelligent robots [15].

In bottle inspection for food processing, the system only classify things as pass or fail where the rule-based system works very well. In this study, since the identification of foreign materials inside the application is on clear-empty glass bottle, one can identify several accepted images and rejecting otherwise.

\section{METHODOLOGY}

\section{A. Rule-based System - A decision system}

The rule-based system for the inspection makes it simpler and faster for the controller to decide whether there is or no foreign materials in the bottle. The filtered images of good samples are needed as fixture references. It undergoes a process of blobs and feature extraction. The initial training sets of images and its features are stored in arrays $\mathrm{B}_{\mathrm{x}}$, as good samples, and $\mathrm{C}_{\mathrm{x}}$, as bad samples (See Fig. 2) These sets are stored to the rule-based system. A user-defined threshold can be adjusted depending on the quality of images produced by the camera used. Threshold Thres is the image quality margin of acceptance from the good samples. A decision formula assesses the images as "PASS" or "FAIL". The evaluated samples are stored in array $D_{x}$. $D_{x}$ with remarks as "PASS" proceeds to filling process, otherwise, it will be ejected.

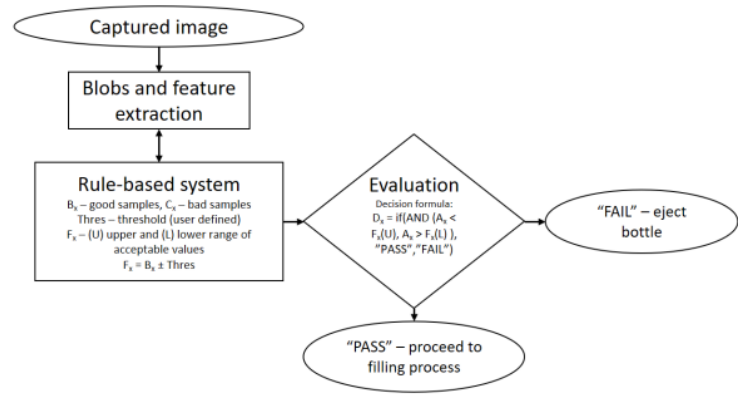

Fig. 2. Rule-based system diagram

\section{B. Automated Optical Inspection}

The machine vision system through an automated optical inspection has the basic setup for this application and considers the following critical points:

1. Imaging Setup - To capture a well-focused image, the camera should be set accordingly. A Locate and Inspect Part command are used for detecting a good glass bottle base that is used in the production. This is done to set the reference images for inspection. A summary of the different lighting methods was presented which became the basis for cost-effective setup which is presented in Table 1. This is a result of the preliminary experiment conducted to determine which type of lighting will be used. The experiment result tells that the backlight illumination is good for this application because of its minimal cost and ability to aid in producing quality images for inspection. See Fig. 3 and 4 for the setup.

2. Lens focal length adjustment - Several trials are conducted to find the optimal setup for the lens focal length adjustments. The field of view (FOV) parameter is the basis of the focal length of the lens. The focal lengths from $6 \mathrm{~mm}, 9 \mathrm{~mm}$, and $12.5 \mathrm{~mm}$ are tested with variation in working distance for each, in $100 \mathrm{~mm}, 150 \mathrm{~mm}, 200 \mathrm{~mm}$, and $250 \mathrm{~mm}$.

3. Camera mounting - the camera is mounted in such that the lens is perpendicular to the clear glass platform centered in the IR backlight as seen in Fig. 3.

4. Monitor or Graphical User Interface - this monitor displays the activities of the automated optical inspection. It also functions as a look-up device wherein parameters can also be monitors.

Table I. SUMMARY OF DIFFERENT TYPES OF ILLUMINATION BASED ON THEIR PERFORMANCE APPLICABILITY TO BOTTLE INSPECTION AND COST

\begin{tabular}{lllll}
\hline \hline $\begin{array}{l}\text { Leg } \\
\text { No. }\end{array}$ & $\begin{array}{c}\text { Type of } \\
\text { Illumination }\end{array}$ & Cost & Rating & Remarks \\
\hline 1 & $\begin{array}{l}\text { Low angle ring } \\
\text { light }\end{array}$ & $\begin{array}{l}\text { Low } \\
\text { cost }\end{array}$ & Poor & $\begin{array}{l}\text { Unable to } \\
\text { detect }\end{array}$ \\
\hline
\end{tabular}




\begin{tabular}{|c|c|c|c|c|}
\hline 2 & Direct bar light & $\begin{array}{l}\text { Low } \\
\text { cost }\end{array}$ & Poor & $\begin{array}{l}\text { Unable to } \\
\text { detect }\end{array}$ \\
\hline 3 & Dome light & $\begin{array}{l}\text { Low } \\
\text { cost }\end{array}$ & Poor & $\begin{array}{l}\text { Unable to } \\
\text { detect }\end{array}$ \\
\hline 4 & $\begin{array}{l}\text { Diffused } \\
\text { coaxial light }\end{array}$ & $\begin{array}{l}\text { High } \\
\text { cost }\end{array}$ & Good & $\begin{array}{l}\text { Foreign } \\
\text { materials are } \\
\text { visible and } \\
\text { detected }\end{array}$ \\
\hline 5 & Back light & Fair & Good & $\begin{array}{l}\text { Foreign } \\
\text { materials are } \\
\text { visible and } \\
\text { detected }\end{array}$ \\
\hline 6 & Flat dome & $\begin{array}{l}\text { Low } \\
\text { cost }\end{array}$ & Poor & $\begin{array}{l}\text { Unable to } \\
\text { detect }\end{array}$ \\
\hline
\end{tabular}

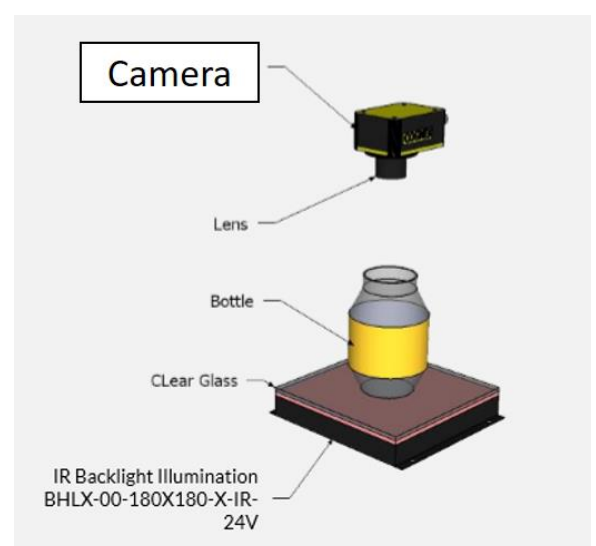

Fig. 3. Basic Inspection Setup.
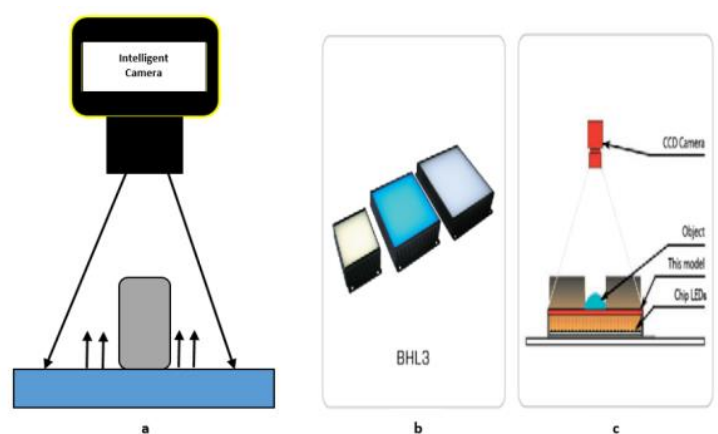

Fig. 4. Back light illumination: a) 2D View, backlight at the bottom b) LED dense array c) diffuse illuminator positioning, CCD-(Cognex IS 7400)

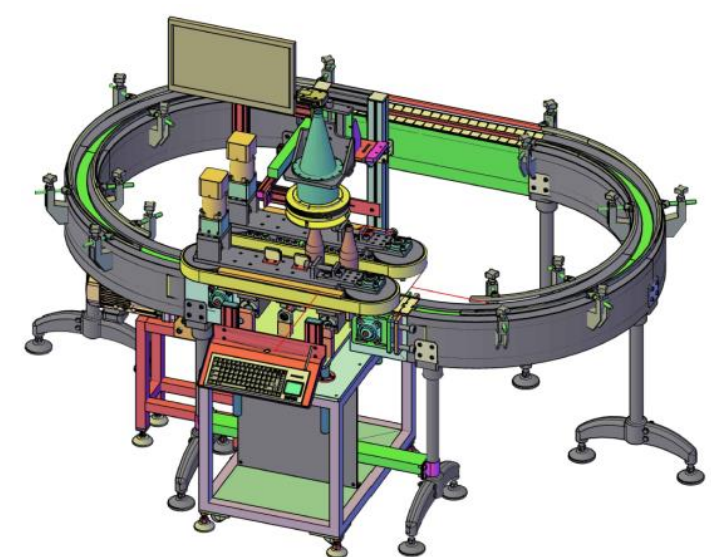

Fig. 5. In-line bottle inspection setup (Image and setup courtesy of Inzpect Technologies Inc.)

\section{In-line bottle inspection setup}

To simulate the inspection, a wedge conveyor machine developed. The speed of the inspection can be tested and recorded in this loop (See Fig. 5). To create a realistic evaluation, an ejecting mechanism and control is added to determine its capability to accurately eject bottles with defects or foreign materials. The actuators for ejecting the defective items and the conveyor system are controlled by a programmable logic controller (PLC). The digital input to the PLC comes from machine vision system.

\section{Results}

\section{A. Actual Setup}

The Locate and Inspect Part in the In-sight Explorer creates grayscale image equivalent which is used as the Fixture Reference for all glass bottle units. The actual setup for the inspection can be seen in Fig. 6. Processing the image with inspection tools detects the features of the image (See Fig. 7). This is the captured image resulting from the setup of the backlight illumination. The positioning of diffuse illuminator can give a silhouette effect on the image. This technique is normally used for applications in 'through holes', depending on the shape of interest or opaque objects with bright or dark image variations are desired. These good samples are recorded as the reference for the "pass" remark.

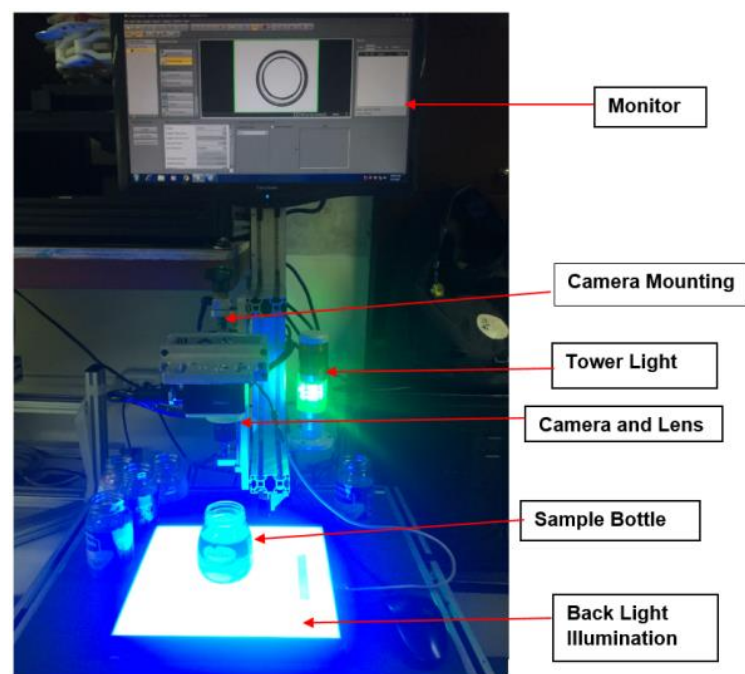

Fig. 6. Actual setup of the inspection trainer 

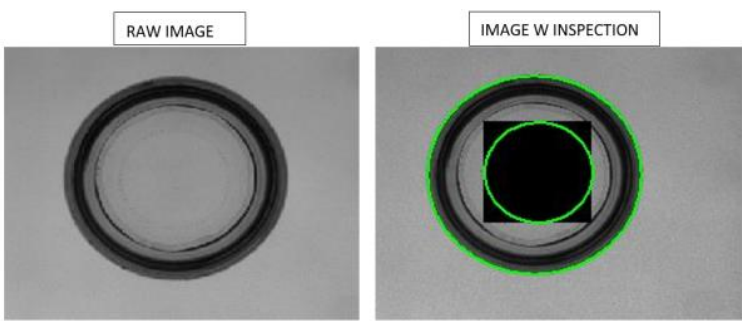

Fig. 7. Grayscale image as a result of locate and inspect part tool in in-sight explorer.

Table II. TEST RESULTS FOR FOCAL LENGTH OF LENS AND ITS WORKING DISTANCE. THE 9MM FOCAL LENGTH AT 100MM WORKING DISTANCE, THE INSPECTION IS ACCURATE.

\begin{tabular}{|c|c|c|c|c|}
\hline $\begin{array}{c}\text { FOCAL LENGTH } \\
\text { OF LENS } \\
\end{array}$ & $\begin{array}{l}\text { WORKING } \\
\text { DISTANCE }\end{array}$ & RESULT & IMAGE & REMARKS \\
\hline \multirow{4}{*}{$6 \mathrm{~mm}$} & 100 & $\begin{array}{l}\text { Smaller } \\
\text { limage but } \\
\text { larger FOV }\end{array}$ & & Not Possible \\
\hline & 150 & $\begin{array}{l}\text { Smaller } \\
\text { image but } \\
\text { larger FOV }\end{array}$ & & $\begin{array}{l}\text { Possible but } \\
\text { lesser } \\
\text { accuracy }\end{array}$ \\
\hline & 200 & Smaller FOV & & \begin{tabular}{|l} 
Possible but \\
lesser \\
accuracy
\end{tabular} \\
\hline & 250 & Smaller FOV & & $\begin{array}{l}\text { Possible but } \\
\text { lesser } \\
\text { accuracy }\end{array}$ \\
\hline \multirow{4}{*}{$9 \mathrm{~mm}$} & 100 & $\begin{array}{l}100 \times 100 \\
\text { FOV was } \\
\text { met with } \\
\text { good quality } \\
\text { image }\end{array}$ & & Possible \\
\hline & 150 & $\begin{array}{l}\text { Smaller } \\
\text { image but } \\
\text { larger FOV }\end{array}$ & & Not Possible \\
\hline & 200 & $\begin{array}{l}\text { Larger FOV } \\
\text { and darker } \\
\text { image }\end{array}$ & & $\begin{array}{l}\text { Possible but } \\
\text { lesser } \\
\text { accuracy }\end{array}$ \\
\hline & 250 & $\begin{array}{l}\text { Larger FOV } \\
\text { and darker } \\
\text { image }\end{array}$ & & $\begin{array}{l}\text { Possible but } \\
\text { lesser } \\
\text { accuracy }\end{array}$ \\
\hline \multirow{4}{*}{$12.5 \mathrm{~mm}$} & 100 & $\begin{array}{l}\text { Larger FOV } \\
\text { and darker } \\
\text { image was } \\
\text { captured }\end{array}$ & & $\begin{array}{l}\text { Possible } \\
\text { but lesser } \\
\text { accuracy }\end{array}$ \\
\hline & 150 & $\begin{array}{l}\text { Greater than } \\
100 \times 100 \\
\text { FOV was } \\
\text { captured, not } \\
\text { the whole } \\
\text { image was } \\
\text { captured }\end{array}$ & & $\begin{array}{l}\text { Not Possible. } \\
\text { View is } \\
\text { already off-set }\end{array}$ \\
\hline & 200 & $\begin{array}{l}100 \times 100 \\
\text { FOV was } \\
\text { captured but } \\
\text { with darker } \\
\text { image }\end{array}$ & & $\begin{array}{l}\text { Possible } \\
\text { but lesser } \\
\text { accuracy }\end{array}$ \\
\hline & 250 & $\begin{array}{l}\text { Larger FOV } \\
\text { and darker } \\
\text { image was } \\
\text { captured }\end{array}$ & & $\begin{array}{l}\text { Possible } \\
\text { but lesser } \\
\text { accuracy }\end{array}$ \\
\hline
\end{tabular}

\section{B. Focal length and distance adjustments}

The best FOV is needed for detecting the foreign materials inside a glass bottle determined through the focal length of the lens and its working distance. Table II summarizes the results of the experiment. At $6 \mathrm{~mm}$ focal length of the lens with working distances at $150 \mathrm{~mm}$ to $250 \mathrm{~mm}$, the detection can be possible but will less accuracy as compared to $9 \mathrm{~mm}$ focal length at $100 \mathrm{~mm}$ working distance, in which the system was able to detect materials. This setup also gives a 100x100 FOV. The focal length of the lens, the working distance, and the FOV can also be calculated through the intelligent camera features.

\section{Rule-based System at work}

The rule-based system implemented in this study uses a training model as a fixture reference which gives positional data upon inspection. This is done through a location tool function in the in-sight explorer. The output is used in a vision-guided inspection.

The defect detection tool is also available in the in-sight explorer with the intelligent camera integration. The advanced edge analysis technique determines the defects such as crack, crimp, dent, gap nick, or scratch. One of the features of this defect detection tool is the surface flaw detection (SFD) which enables the system to detect such defects (See Fig. 8). SFD is based on pixel intensity variations. Flaws greater than the user defined threshold, SFD sends a fail signal and returns a list of flaws and their statistical parameters and features, which includes the area, roundness, and the perimeter.

The speed of detection in the wedge loop conveyor was recorded to be in an average of 9000 bottles per hour (bph). This speed has competitive advantage since setup is simple and has minimal cost. In actual setup it is projected to be in speed of 18000 bph.

\section{Validation}

To validate the system performance, several materials were tested. There were 5 samples for each: known good sample bottles, metals of different sizes, small wood particles, glass splinter, wire, clear plastic of $10 \times 10 \mathrm{~mm}$ size. All of the good sample bottles were evaluated as "pass" and all of the sample foreign materials were being detected and evaluated as "fail". The GUI display can be seen in Fig. 9. 10 trials have been conducted and they all achieved $100 \%$ accuracy. 


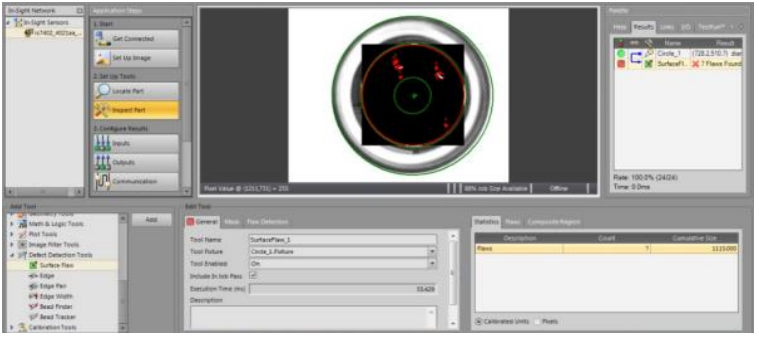

Fig. 8. Surface flaw detection.

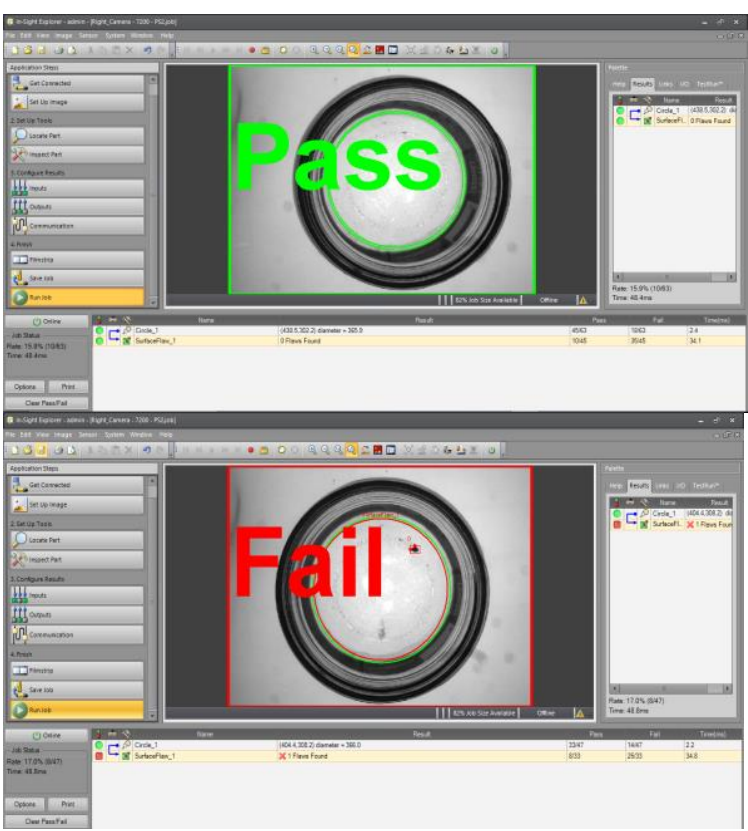

Fig. 9. Inspection using In-Sight Explorer, evaluating the inspected bottles as "pass" or "fail"

\section{Conclusion}

A fast and accurate inspection of the clear-empty glass base can be achieved through a rule-based machine vision system. The rule-based approach uses lesser data set compared to other methods of evaluating captured images using CCD digital cameras. The logical operations of the decision formula are effective in evaluating the processed image and identifying defects on the empty glass. At $9 \mathrm{~mm}$ focal length with $100 \mathrm{~mm}$ working distance of the camera from the bottle, the system was able to accurately evaluate the samples. The backlight illumination has been presented as a cost-effective way for this application. The machine vision system setup presented was validated through an in-line loop in a wedge conveyor machine prototype for inspection. The speed of detection of the overall system results to a 9000-18000 bph. The methods presented are beneficial and fit for MSMEs in the Philippines with bottle inspections with a low upfront cost.

In the future, the study on full bottle inspection will be conducted considering the neck and the lip.
Further enhancement of the methods with costeffective benefits will be searched out.

\section{ACKNOWLEDGMENT}

The authors first acknowledge the Lord Jesus Christ for His guidance and provision. This is accomplished with the guidance of the academicians from the Bachelor of Engineering and Allied Department of the Technological University of the Philippines Taguig. The support from Inzpect Technologies Inc. is also acknowledged, for providing equipment for experimentation.

\section{REFERENCES}

[1] SETUP (Small Enterprise Technology Upgrading Program) Retrieved from:

https://ncr.dost.gov.ph/index.php/what-wedo/technology-transfer/community-empowermentthru-science-and-technology

[2] S. Gunasekaran. (1996). Computer Vision Technology for Food Quality Assurance, 71(August), 245-256.

[3] Y. Wang. (2008). Development of a Computerized Method to Inspect Empty Glass Bottle, 2008 Int. Symp. Comput. Sci. Comput. Technol, 2, 118-123.

[4] A. Visual. (2012). Automated Visual Inspection 20, pp. 525-552.

[5] H. Liu \& Y. Wang. (2008). Development of Glass Bottle Inspector Based on Machine Vision, 2008 10th Int. Conf. Control. Autom. Robot. Vis., no. December, pp. $785-790$

[6] T. Nakashima, Y. Shoji \& G. Schaefer. (2008). CostSensitive Techniques for Fuzzy Rule-Based Pattern Classification, pp. 1-6.

[7] Z. Wen \& Y. Tao. (1999). Building a rule-based machine-vision system for defect inspection on apple sorting and packing lines, 2008 World Automation Congress, 16, 307-313.

[8] S. E. Group. (1991). Object-oriented Programming Languages for Real-time Rule-based Systems: A Practical Evaluation, no. October.

[9] N. Mort, S.J. Carter \& D.C. Langbridge. (1989). Experiences with Rule-based Control Algorithms in a Teaching Laboratory and a Diesel Engine Test Cell."

[10] D. Haspel. (1985). The Role of Rule-based Control in the Process Industry. pp. 2-4.

[11] G.P. Spaven A.W, Self, D.F. Pearce. (1988). The Development of an Industrial Rule-based Computer Vision Control System.

[12] M. S. Marshall. Object-oriented Rule-based I m a g e Segmentation System, no. ii, 167-171.

[13] R. Cucchiara, M. Piccardi \& P. Mello. (1999). Image Analysis and Rule-based Reasoning for a Traffic Monitoring System.

[14] P. Tosanguan \& T. Suwannasart. (2012). Rule-Based Software Development," Seventh Int. Conf. Digit. Inf. Manag. (ICDIM 2012), 30-34.

[15] Y. Wang, Q. Wang \& R. Liu. (2009). A Rule-based Decision Subsystem Design Approach for Intelligent Robot, 2009 ISECS Int. Colloq. Comput. Commun. Control. Manag., vol. 2, 525-528. 